\title{
The Inclusion of Academicians into the Industry Sector in Bangladesh: A Model of Industry Engagement and Effective Innovation Performance
}

\author{
Mostak Ahamed Galib, Kamrun Nahar Munny \\ School of Management Science and Engineering, Wuhan University of Technology, Wuhan, China \\ European University of Bangladesh, Dhaka, Bangladesh \\ Email (corresponding author): ahmed_galib@hotmail.com
}

\begin{abstract}
Through a detailed review of all factors belonging to the scope of motives that are opportunity-driven, key factors that are most conducive to researchers' industry engagement have been identified. The relationships between compensation and recognition, access to resources, belief about application of the research, networking opportunities, and industry problem solving with industry engagement were tested. The study design is mixed method with two phases. The first qualitative phase has surfaced potentially significant factors. The second quantitative phase addresses the survey's validity, reliability, and design and uses a web-enabled survey to collect data from university academicians and researchers in institutes using a single stage, cross-sectional approach. Inference statistics and Structure Equation Modeling (SEM) were utilized to evaluate the research model. The study has been done on a sample of university and research institute employees in Bangladesh. This study proposes industry engagement model in order to improve organizational learning capability and innovation performance. According to the results application of research and access to resources are significant drivers of industry engagement. Furthermore, industry engagement was confirmed as factor influencing organizational learning capability and organizational innovation performance. The study is valuable for organizations and government policy-makers given that the importance of industry engagement for organizational outcomes has been confirmed. Correspondingly, significant implications for organizations exist, as they are aware of which parts of their operations and conditions will drive relevant talent to engage in the organizations' work.
\end{abstract}

Keywords: Industry engagement, motives for industry engagement, organizational learning capability, organizational innovation performance, Bangladesh

\section{Introduction}

With regard to firms, collaboration with universities is fundamental to access highly qualified engineers. The best way to recruit them is by directly testing their abilities during joint research. Ideas, solutions to problems, models delivered by university professors are also very important, and the establishment of direct personal links allows firms to tap professors' expertise. Ultimately, joint research with universities allows companies to leverage matching research funds from government. Industry is generally more interested in short-term problems and empirical research that can assist either in solving a problem or in providing the foundations for commercializable technologies and products, rather than focusing on how industry funding and other industry resources can — pulll researchers to be involved with industry. Given that work engagement is a critical factor to subsequent performance, it is important to investigate the extent to which various factors, contribute to engagement.

The study planned aims to fill the existing theoretical gaps in the field of industry engagement and innovation performance and provide recommendations for the practice on how to solve the problem of insufficient involvement of 


\section{Mostak Ahamed Galib, Kamrun Nahar Munny \\ The Inclusion of Academicians into the Industry Sector in Bangladesh: A Model of Industry Engagement and Effective Innovation Performance}

researchers in the industry sector and lack of collaboration between industry and research institutes. The existing studies have failed to quantitatively evaluate motives' contribution to industry engagement. Without knowing the key motives valid organizational practices for industry engagement enhancement cannot be designed and implemented. There is a need to fill the gap between scientific discoveries and industry applicability be it driven by intrinsic or extrinsic reasons from the researchers' perspective.

The study aims to answer these questions:

(1) What are the most important motives for researchers to engage in industry work?

(2) Which specific motive has the highest predictive value for industry engagement?

(3) Does academicians/researchers' industry engagement lead to organizational innovation?

(4) Does academicians/researchers' industry engagement lead to organizational learning capability?

We explore how various factors which researchers have identified as relevant as motivators affect individuals' industry engagement, which encompasses the various ways that academic scientists collaborate with third-party organizations, and includes collaborative research, contract research and consulting as well as informal networking with practitioners (Perkmann et al., 2013). Academic engagement involves a large proportion of academic scientists across many disciplines, generates income for universities and may result in commercialization extending to licensing of patents and spinout activities (Perkmann et al., 2013). Given the relevance of academics' engagement with industry for innovation and problem-solving (Cohen et al., 2002), it is important to develop a detailed understanding of what drives scientists' collaboration and industry engagement. The literature on university-industry relationships suggests that different motivational factors might be when academics interact with industry.

In next section, we identify specific factors of incentives (recognition, rewards, income), networking (social capital), access to resources, research drive (industry problem solving, and application of research) have been identified by various studies as key factors for industry engagement, however, a quantitative study will determine the predictive value of each factor. Additionally, we will determine the impact of researchers' industry engagement toward organizational learning capability and organizational innovation performance as specified in the conceptual model. Finally, given that the study is conducted in the context of Bangladesh, a valuable insight in academia and industry of developing country will be provided.

\section{Theoretical review and conceptual model}

The literature on researchers' engagement in industry shows that the engagement choices are governed by a wide variety of factors, including inter-institutional structures (Landry and Amara, 1998); formal (Wen and Kobayashi, 2001) and informal research networks; research alliances and covenants (Pisano, 1991); and arrangements for sharing expensive or scarce scientific resources and equipment (Kelves, 1995). Moving from macro to micro, one can notice that intertwined with these structural and institutional factors are more individual concerning reasons for engagement with industry. Being involved with industry takes both a desire to be involved with industry and the ability to move beyond theoretical, curiosity driven research. Industry is generally more interested in short-term problems and empirical research that can assist either in solving a problem or in providing the foundations for commercializable technologies and products.

\section{Motives Influencing Researchers' Industry Engagement}

\section{Compensation and recognition}

According to the motivational theories financial security and stability have shown to be significant drivers of engagement in certain activities and performance of behaviors. Prior studies establish a direct relationship between incentives (income, rewards, and bonuses) and industry engagement. Economic compensation is considered an important motivator which was proven by Deeprose (1994) that incentives in the form of money may not be the best motivator but without it is many engaged scientists will be strongly de-motivated. Economic rewards are highly valuable in showing the worthy of work done by an employee in our case an industry involved researcher to increase 


\section{Mostak Ahamed Galib, Kamrun Nahar Munny \\ The Inclusion of Academicians into the Industry Sector in Bangladesh: A Model of Industry Engagement and Effective Innovation Performance}

their self-esteem and sense of achievement that is essential for their reputational status. This above supporting arguments and literature leads to the development of the following hypothesis;

H1: Compensation has a positive relationship with industry engagement

Academic life cycle theory shows that scientists invest more in their human capital and reputation development at earlier stages of their careers. Some scientists value reputation and recognition of their research work accomplished more than monetary compensation. The early study done by Merton (1957) demonstrated that among the main factors leading scientists to do research in the industry is recognition. Traces regarding the significance of reputation as a motivating force in science are readily apparent. In the process of project participation scientist perform behaviors which often results in positive outcomes.

H2: Recognition has a positive relationship with industry engagement

\section{Networking}

Networking deracinates immense thinking and talents out of different people to promote learning, creativity and innovation. When similar and different minded people meet the exchange and sharing of ideas is open that stretches creativity and innovation by gaining new concepts, perspectives or creative ways in handling tasks and thinking is acquired. Prying on the benefits leading to scientists to engage in industry based networking especially for those that intend to startup their own businesses, networking helps them to grow and gain a better position in their business operations. Networking in the industry is great for this regard because the value of networking is in the giving and receiving sort of beneficial exchange.

H3: Networking has a positive relationship with industry engagement.

\section{Access to resources}

Materials and data are necessary for any research, in order to bring out the quality research, such materials and data may be obtained in the industry which compels researchers toward industry involvement. There exist a gap between data obtained by an outside researcher and an industry involved researcher who observes and is practically involved in the activities. Additionally, motive for industry engagement also includes the search for advice on practical matters, opinion and resolution.

H4: Access to resources has a positive relationship with industry engagement.

\section{Industry problem solving}

Among the motives that drive researchers into industry involvement is to find answers and solutions to problems imminent in industries and also disclose problems caused by activities of the industry. Researchers have a wide variety of research interests, some focus on accelerating innovations in the production process and some are focus on cooperate and social responsibility by advocating and pushing industries to embrace cleaner productions in their activities. The theory of inventive problem solving encourages the search for innovative solutions to support the growing need for cooperate and social responsibility through promoting cleaner industrial operations. Researchers are not just ambitious in finding solutions in accelerating production capacity but also to solve industrial production problems, discover weaknesses and develop opportunities within the industry and serve as an innovative instrument as a researcher to find ways to improve environmental efficiency.

H5: Industry problem solving has a positive relationship with industry engagement.

\section{Application of research}

As for researchers to be involved in the industry gives them a chance to prove their theoretical, and curiosity driven research that is applied practically in the industry. The application of research focuses on researchers to initiative the increasing prospect of research application outside academia into the industry. According to study by Hawkins, et al. (2012) indicated that $74.5 \%$ of researchers regarded applicability of research as highly important factor driving researchers toward industrial engagement. While $11.1 \%$ of researchers engage to seek IP right (Hawkins, et al., 2012) s. Researchers contribute to industry by applying their studied methods in the seminars, publications on proven practices, developing informative scientific prints and research projects, and getting a team together working toward a common goal, considering ethics of research, transforming research findings into industry practice.

Some reasons behind industrial engagement concerning application of research are listed below; 
- Keeping abreast of research conducted in the industry

- Feedback from industry on viability of research

- Exploitation of research capabilities and results or deployment know-how to obtain patents

- Test application of ideas or theory aimed to explain and commercialize the ideas to the industry

- Pursuing proprietary knowledge (patents)

- Promote innovation through knowledge and technology transfer

- Academics' quest for recognition and achieve eminence and prestige

H6: Application of research motive has a positive relationship with industry engagement.

\section{Industry Engagement Effects}

There is a positive effect of scientists engaging in industry on organizational innovation performance. As Balachandra and Friar (1997) state the lifeblood for most organizations is bringing new products successfully to market. Research and Development (R\&D) is the basis of product and process innovations. Significant attention has been given to linkage of industry engagement to innovation results of organizations. Several studies observe that when scientists engage in the industry it initially results in greater employee performance, which further leads to enhanced organizational performance, in terms of innovation (Perrin, 2006; Gallup, 2006).

H7: Industry engagement positively influence organizational innovation performance.

Industry engagement is important for knowledge creation, knowledge retention, and knowledge transfer which can be seen as adaptive processes of organizational learning. Experience of scientist in a particular subject is transferred into an organization. This is the knowledge that adds to the understanding of a subject through industry involvement or exposure. When scientists engage in the industry, they become part of the organization team that allows a smooth flow of information contributing to organizational learning.

H8: Industry engagement positively influence organizational learning

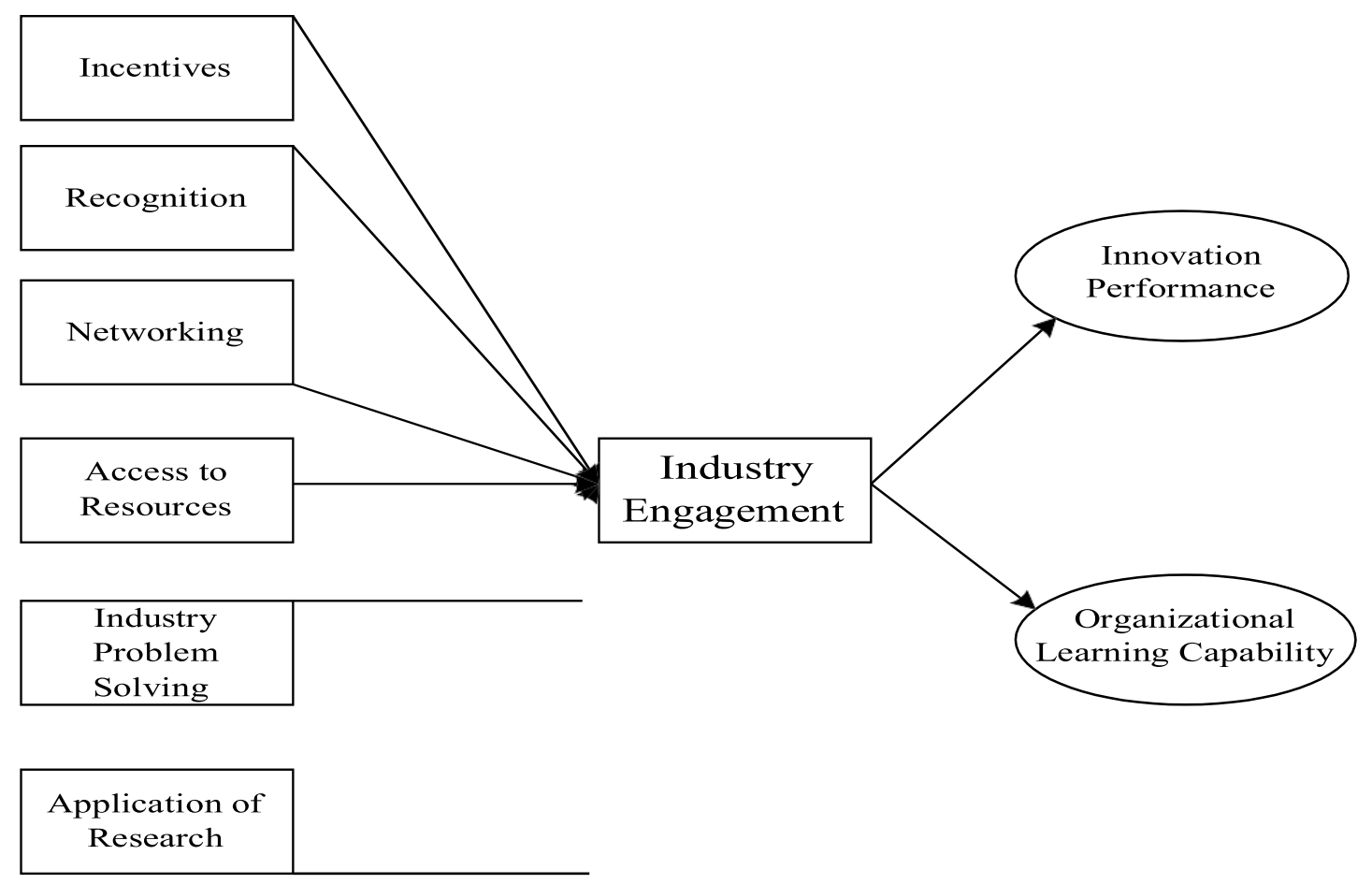

Research model

The research model depicts the possible generation of the industry engagement as an outcome, which, in turn leads to organizational innovation. Through a detailed review of all factors belonging to the scope of motives that opportunitydriven have key factors that are most conducive to researchers' industry engagement have been identified. Therefore, 


\section{Mostak Ahamed Galib, Kamrun Nahar Munny \\ The Inclusion of Academicians into the Industry Sector in Bangladesh: A Model of Industry Engagement and Effective Innovation Performance}

we have hypothesized the relationship between income and recognition, access to resources, belief about application of the research, networking opportunities, industry problem solving and industry engagement.

\section{Methodology of the study}

This research adopted a quantitative method by using a cross-sectional design on Industry Engagement and Effective Innovation Performance. For this study, 100 universities and institutes were selected: all from the Bangladesh metropolis and provincial areas. Questionnaires were sent out to all employees in institutes and universities with industry experience with the goal of explaining Industry engagement of researchers in the present survey. Questionnaires were administered to a total of 500 employees, producing 326 returns, and with an overall response rate of $65.2 \%$. The missing values were eliminated from the sample and only 142 respondents were taken into consideration. The respondents of the questionnaire were University scientists, academics at various institutes in Bangladesh and that were all employed in industrial projects as consultants or specialists in their field of study. Most of the respondents were university and institution academics and professors with a $\mathrm{PhD}$ or higher qualification. The majority of the respondents were engaged in the scientific, engineering, academic and education services.

\section{Variables}

The variables included in this research were as follows: Compensation Seeking, Recognition Seeking, Networking, Industry Problem Solving, Access to Resources, Application of Research, Industry Engagement, Organizational Learning Capability, and Organizational Innovation Performance. The factors are evaluated on a scale from 1-7 from strongly disagree to strongly agree.

\section{Compensation seeking}

Specifically, intrinsic motivation has been found to include challenge seeking and task enjoyment, whereas extrinsic motivation has been found to include compensation seeking and recognition seeking, and these first-order motivation components are conceptually and empirically distinct (Amabile et al., 1994). This study deployed four items to verify compensation seeking, which assesses if an individual is strongly motivated by the money he can earn through his industry involvement and if the person is keenly aware of the promotion goals one has set for himself (Tyagi, 1985).

\section{Recognition seeking}

Recognition seeking tends to focus salespeople's attention on the required selling activity of the immediate supervisor (Kohli et al., 2003) thereby increasing salesperson's selling effort. Recognition seeking was measured and is operating four items and trying to assess if a person is concerned about how other people are going to react to his performance or if an individual wants other people to find out how good he can really be at my work.

\section{Networking}

Networking implies a group of acquaintances and associates and keeping it active through regular communication for mutual benefit. Five items adopted from Tsai and Ghoshal measured in trying to figure out if an individual maintains good networking with colleagues from the industry sector, maintains close social relationships with friends or partners in the industry sector or has I has frequent communication with some colleagues of the industry sector.

\section{Industry Problem Solving}

The industry problem solving variable was measured using a 8 -item scale (Fuentes and Dutrénit, 2012) and is generally based on of using generic or ad hoc methods, in an orderly manner, for finding solutions to problems.

\section{Access to Resources}

A five item scale was used to measure the access to resources (items reported here builds on D'Este and Patel (2007)). The access to resources is measured by determining if part of a larger research group develops higher quality research within the industry sector, if an individual has access to superior equipment and infrastructure which industry offers and if he has access to open science/information within the industry sector (Fuentes and Dutrénit, 2012). 


\section{Mostak Ahamed Galib, Kamrun Nahar Munny \\ The Inclusion of Academicians into the Industry Sector in Bangladesh: A Model of Industry Engagement and Effective Innovation Performance}

\section{Application of Research}

According to Belkhodja and Landry (2007) application of research involves the researcher's participation and contribution to the industry: which we measure using the scale of Employee Participation by (Evers et al. 2000). The application of research was measured trying to determine if an individual can influence how the work is divided among him and his colleagues within the industry sector, if he can participate in making decisions concerning his work within the industry sector and if he is able to directly influence decisions concerning my part of the organization.

\section{Industry Engagement}

Dependent variable of industry engagement was measured with a scale adopted from Bozeman and Gaughan (2007). To see the extent of industry engagement, eight items were used to figure out if the researcher contacted persons in industry about their research, if the researcher worked at a company at which he is an owner or employee, if he worked directly with industry in work that resulted in a patent or copyright and also worked directly with industry in effort to commercialize or transfer technology.

\section{Organizational Learning Capability and Innovation Performance}

Output variables of organizational learning capability and innovation performance were measured by the established measurement tools developed that have been validated in various studies. Organizational learning consists of the acquisition, dissemination and use of knowledge (Argote et al., 2003), and is therefore an extremely useful process for generating new ideas. Previous research suggests that organizational learning affects positively export intensity. We conceive innovation performance as a construct with three different dimensions consistent with the previous literature: product and process innovation effectiveness, and innovation efficiency (Appendix). These dimensions have been widely discussed in innovation research (Brown and Eisenhardt, 1995).

\section{Data analysis and results}

The analysis process was conducted in three main parts. First, the descriptive statistics were calculated and normality of data has been assessed in order to be able to continue with further analysis. In table, the values for mean, standard deviation, skewness, kurtosis, minimum and maximum are shown. The missing values were eliminated from the sample and only 142 respondents were taken into consideration. The mean values ranged from 3,88 - 5,69 with the lowest value belonging to Industry engagement being, and the highest to networking.

Construct validity was assessed using factor analysis. Consequently, confirmatory factory analysis was performed in order to confirm the factor structure. Nine factors were extracted, explaining majority of variance in the data. Furthermore, all nine factors have eigenvalues larger than 1.00, with eigenvalues for the nine factors ranging from 1.750 to 25.02 , and therefore were retained. The total eigenvalues from highest to lowest were as follows: 25,052, $5,134,3,624,2,930,2,743.2,463,2,165,1,850$ and 1,750 .

\section{Effects of industry engagement on organizational learning capability and innovation performance}

According to the proposed model, there is a positive linear relationship between organization innovation performance and organization learning capability as outcomes and industry engagement as an input variable. In order to assess independent effects of industry engagement on organizational innovation performance and organizational learning capability, correlation analysis and multiple regression were performed on data points available after the removal of the data points with empty fields. Before performing the regression, assumption of linearity was confirmed and normal distribution of data points was ascertained. After performing the regression, choice of the model was justified by performing the residual plot. Correlation coefficient $\mathrm{r}(140)=0.74$ organization learning capability and innovation performance sharing was obtained.

Correlation coefficients between variables of the research model

\begin{tabular}{|c|c|c|c|c|c|c|c|c|}
\hline Variable & & $\begin{array}{c}\text { Compensation } \\
\text { Seeking }\end{array}$ & $\begin{array}{c}\text { Recognition } \\
\text { Seeking }\end{array}$ & Networking & $\begin{array}{l}\text { Industry } \\
\text { Problem } \\
\text { Solving }\end{array}$ & $\begin{array}{l}\text { Access to } \\
\text { Resources }\end{array}$ & $\begin{array}{l}\text { Application } \\
\text { of Research }\end{array}$ & $\begin{array}{c}\text { Industry } \\
\text { Engagement }\end{array}$ \\
\hline $\begin{array}{l}\text { Compensation } \\
\text { Seeking }\end{array}$ & $\begin{array}{l}\text { Pearson } \\
\text { Correlation }\end{array}$ & 1 &, $258^{* *}$ &, $330^{* *}$ &, $242^{* *}$ &, $219^{* *}$ &, $269^{* *}$ &, $208^{*}$ \\
\hline
\end{tabular}


Mostak Ahamed Galib, Kamrun Nahar Munny

The Inclusion of Academicians into the Industry Sector in Bangladesh: A Model of Industry Engagement and Effective Innovation Performance

\begin{tabular}{|c|c|c|c|c|c|c|c|c|}
\hline & $\begin{array}{l}\text { Sig. (2- } \\
\text { tailed) }\end{array}$ & &, 002 &, 000 &, 004 & ,009 &, 001 &, 013 \\
\hline \multirow[b]{2}{*}{$\begin{array}{l}\text { Recognition } \\
\text { Seeking }\end{array}$} & $\begin{array}{l}\text { Pearson } \\
\text { Correlation }\end{array}$ &, $258^{* *}$ & 1 &, $272^{* *}$ &, $241^{* *}$ &, $263^{* *}$ &, $182^{*}$ &, $221^{* *}$ \\
\hline & $\begin{array}{l}\text { Sig. }(2- \\
\text { tailed) }\end{array}$ &, 002 & & ,001 &, 004 &, 002 &, 030 &, 008 \\
\hline & $\begin{array}{l}\text { Pearson } \\
\text { Correlation }\end{array}$ &, $330^{* *}$ &, $272^{* *}$ & 1 &, $574^{* *}$ &, $439^{* *}$ &, $518^{* *}$ &, $418^{* *}$ \\
\hline Networking & $\begin{array}{l}\text { Sig. (2- } \\
\text { tailed) }\end{array}$ &, 000 &, 001 & &, 000 &, 000 &, 000 &, 000 \\
\hline & $\begin{array}{l}\text { Pearson } \\
\text { Correlation }\end{array}$ &, $242^{* *}$ &, $241^{* *}$ &, $574^{* *}$ & 1 &, $584^{* *}$ &, $588^{* *}$ &, $499^{* *}$ \\
\hline $\begin{array}{l}\text { Industry } \\
\text { Problem Solving }\end{array}$ & $\begin{array}{l}\text { Sig. }(2- \\
\text { tailed) }\end{array}$ &, 004 & ,004 &, 000 & &, 000 &, 000 &, 000 \\
\hline \multirow[b]{2}{*}{$\begin{array}{l}\text { Access to } \\
\text { Resources }\end{array}$} & $\begin{array}{l}\text { Pearson } \\
\text { Correlation }\end{array}$ &, $219^{* *}$ &, $263^{* *}$ &, $439^{* *}$ &, $584^{* *}$ & 1 &, $516^{* *}$ &, $576^{* *}$ \\
\hline & $\begin{array}{l}\text { Sig. }(2- \\
\text { tailed) }\end{array}$ & ,009 & ,002 &, 000 &, 000 & &, 000 &, 000 \\
\hline \multirow[b]{2}{*}{$\begin{array}{l}\text { Application of } \\
\text { Research }\end{array}$} & $\begin{array}{l}\text { Pearson } \\
\text { Correlation }\end{array}$ &, $269^{* *}$ &, $182^{*}$ &, $518^{* *}$ &, $588^{* *}$ &, $516^{* *}$ & 1 &, $548^{* *}$ \\
\hline & $\begin{array}{l}\text { Sig. }(2- \\
\text { tailed) }\end{array}$ &, 001 &, 030 &, 000 &, 000 &, 000 & &, 000 \\
\hline \multirow[b]{2}{*}{$\begin{array}{l}\text { Industry } \\
\text { Engagement }\end{array}$} & $\begin{array}{l}\text { Pearson } \\
\text { Correlation }\end{array}$ &, $208^{*}$ &, $221^{* *}$ &, $418^{* *}$ &, $499^{* *}$ &, $576^{* *}$ &, $548^{* *}$ & 1 \\
\hline & $\begin{array}{l}\text { Sig. (2- } \\
\text { tailed) }\end{array}$ &, 013 &, 008 &, 000 &, 000 &, 000 &, 000 & \\
\hline
\end{tabular}

**. Correlation is significant at the 0.01 level (2-tailed).

*. Correlation is significant at the 0.05 level (2-tailed).

Model testing industry engagement as predictor of organizational innovation performance had the highest adjusted $\mathrm{R}^{2}$ $=0.316$ among the candidate models and was therefore chosen. Predictive power of the model, expressed by the $\mathrm{R}^{2}=0.316$, indicates that $31.6 \%$ of variance in organizational performance can be explained by industry engagement.

\section{Regression analysis summary}

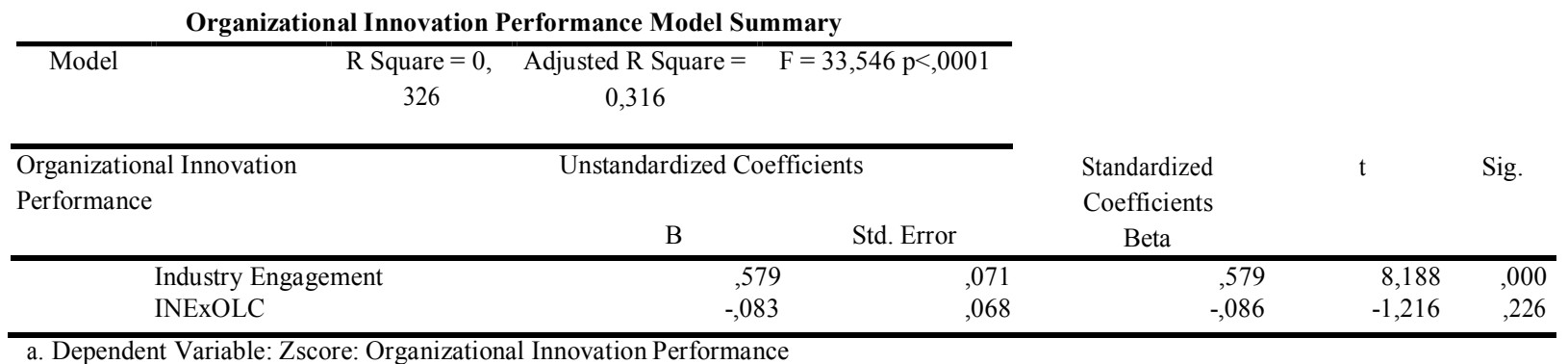

Organizational Learning Capability Model Summary

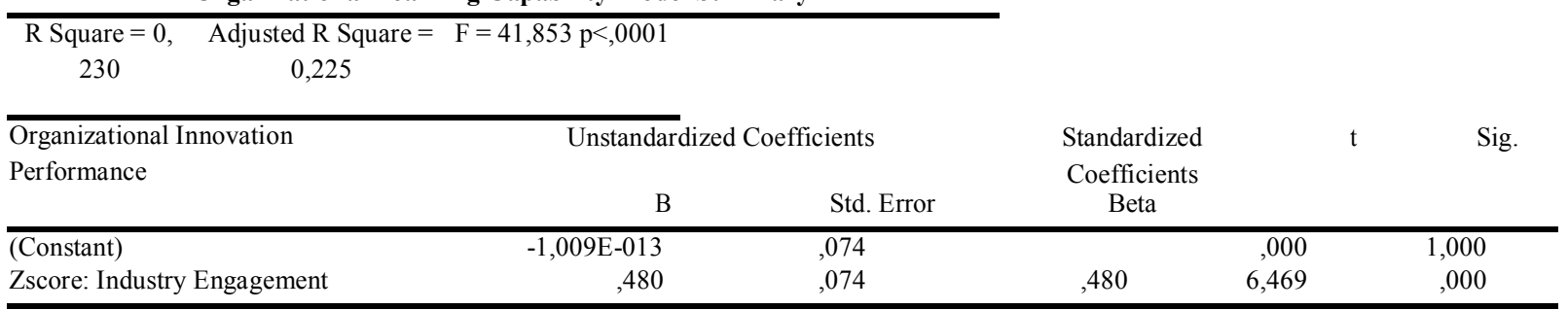


Table also shows the quality of model testing industry engagement as predictor of organizational learning capability with the adjusted $\mathrm{R}^{2}=0.225$. Predictive power of the model, expressed by the $\mathrm{R}^{2}=0.225$, indicates that $22.5 \%$ of variance in organizational performance can be explained by industry engagement. Next, a relative contribution of each independent variable to the total variance explained is determined. Moderate percentage of variance in innovation performance and learning capability can be explained by varying industry engagement, suggesting that additional effects unaccounted for by the model are present. There is a linear relationship between innovation performance and learning capability as outcomes and industry engagement as predictors.

\section{Effects of motivator constructs on industry engagement}

Effects of compensation, recognition, networking, access to resources, industry problem solving, application of research on industry engagement is evaluated.

\section{Industry engagement sharing regression analysis}

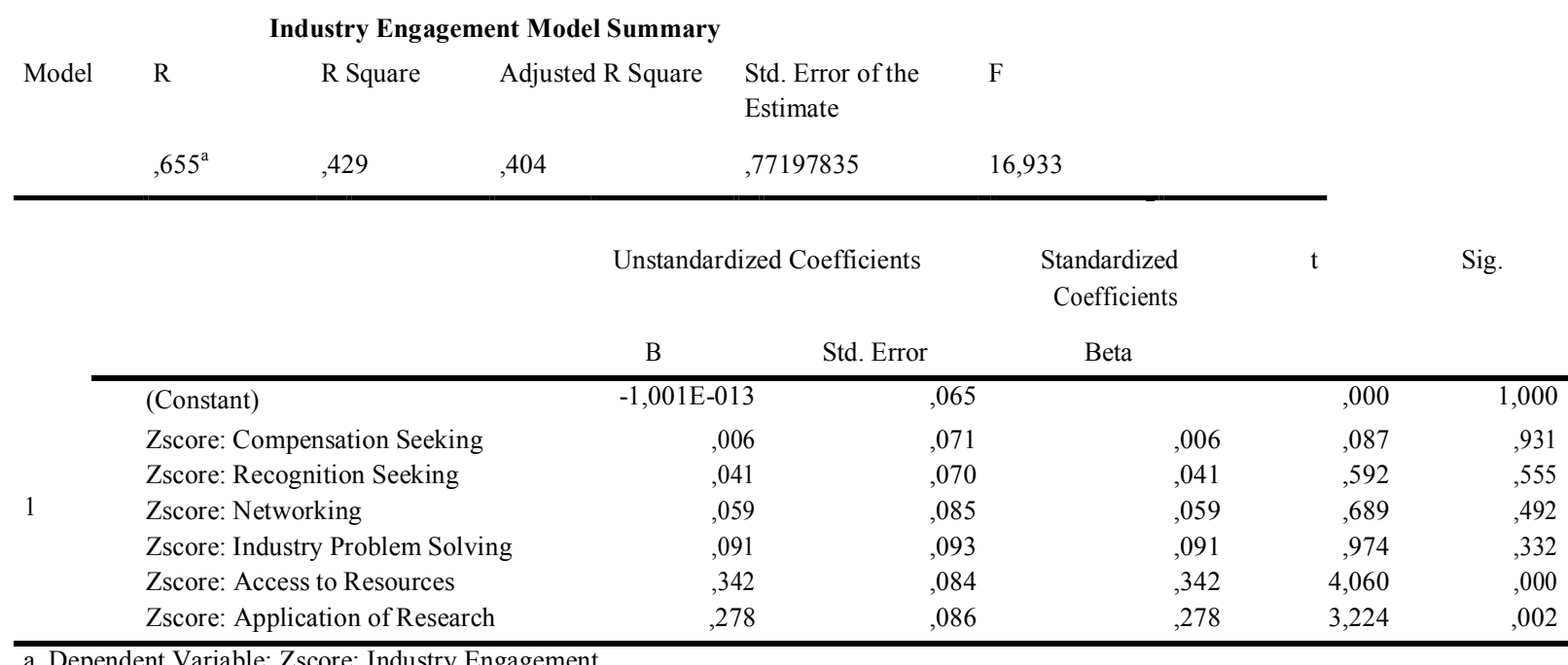

Given that the predictors and the outcome are continuous, quality of model is assessed using the $\mathrm{R}^{2}$ value with obtained value of $R^{2}=0.429 . R^{2}$ value characterizes predictive power of the model. A moderate percentage of variance in industry engagement can be explained by varying compensation, recognition, networking, access to resources, industry problem solving, application of research, suggesting that additional effects unaccounted for by the model are present. Predictive relationship between industry engagement as an outcome and compensation, recognition, networking, access to resources, industry problem solving, application of research as predictors is confirmed. Both regression coefficients for application of research and access to resource as independent predictors are highly statistically significant In the process of hypotheses testing first null hypothesis is defined as $\mathrm{H} 0$ : = hypothesizing opposite of the posited relationship. For the mean regression coefficients, with $95 \%$ confidence null hypothesis can be rejected at $\mathrm{p}<0.005$. Therefore, we concluded that the following hypotheses were accepted:

\begin{tabular}{|l|l|}
\hline H3 & Access to resources has a positive relationship with industry engagement \\
\hline H5 & Research application has a positive relationship with industry engagement \\
\hline H7 & $\begin{array}{l}\text { Industry engagement of researchers has a significant positive influence on organizational } \\
\text { innovation }\end{array}$ \\
\hline H8 & $\begin{array}{l}\text { Industry engagement of researchers has a significant positive influence on organizational } \\
\text { learning capability }\end{array}$ \\
\hline
\end{tabular}




\section{Mostak Ahamed Galib, Kamrun Nahar Munny \\ The Inclusion of Academicians into the Industry Sector in Bangladesh: A Model of Industry Engagement and Effective Innovation Performance}

On the other hand, these hypotheses were rejected:

\begin{tabular}{|l|l|}
\hline$H 1$ & Compensation has a positive relationship with industry engagement \\
\hline H2 & Recognition has a positive relationship with industry engagement \\
\hline H4 & Industry problem solving has a positive relationship with industry engagement \\
\hline H6 & Networking has a positive relationship with industry engagement \\
\hline
\end{tabular}

\section{Discussion and implications of the study}

The findings of the study encompass identification of the exact value of each motive for the researchers' industry engagement. Through a detailed review of all factors belonging to the scope of motives that are opportunity-driven, key factors that are most conducive to researchers' industry engagement have been recognized. We have hypothesized the relationship between compensation and recognition, access to resources, belief about application of the research, networking opportunities, and industry problem solving with industry engagement. According to the results application of research and access to resources are significant drivers of industry engagement. Furthermore, industry engagement was confirmed as factor influencing organizational learning capability and organizational innovation performance. Our study provides novel empirical evidence on an aspect of university-industry relationships where existing studies are ambiguous and incomplete. Overall, we examine the industry involvement, organizational innovation performance and organizational learning capability in Bangladesh organizations.

\section{Key factors leading to industry engagement}

Access to resources has been confirmed as an influential factor for industry engagement in our study. Materials and data are necessary for any research, in order to bring out the quality research. Such materials and data may be obtained in the industry which compels researchers toward industry involvement. There exist a gap between data obtained by an outside researcher and an industry involved researcher who observes and is practically involved in the activities. Among the motives of researchers engaging in industry is attributed to accessibility of the state of art equipment, facilities and instrument. Our findings suggest that application of research is a factor conducive for industry involvement. As for researchers to be involved in the industry gives them a chance to prove their theoretical, and curiosity driven research that is applied practically in the industry. The application of research focuses on researchers to initiative the increasing prospect of research application outside academia into the industry. According to study by Hawkins, et al. (2012) indicated that $74.5 \%$ of researchers regarded applicability of research as highly important factor driving researchers toward industrial engagement.

\section{Industry engagement and organizational outcomes}

Our finding that industry engagement is an important factor for generating organization innovation performance is in line with existing studies. Innovation requires the implementation of creative ideas which scientists effectively bring into realization through research. Organizations apply these research results into the system by a process called organizational learning. Industry engagement has an impact on organizational learning capability and embraces knowledge creation concept whereby information acts as the meaningful input that pave ways of learning process. Experience of scientist in a particular subject is transferred into an organization, this is the knowledge that adds to the understanding of a subject through industry involvement or exposure. Our study suggests that individual behaviour is shaped to a great extent by application of research and access to resources. Therefore, those two factors appear to have a major influence on the individual's decision to engage in behaviour that is not unequivocally prescribed by organizational policies. These results constitute an empirical contribution to the study of the success of cooperative agreements between firms and research organizations. In this way, we have obtained a series of conclusions and implications that can be of great use, both in the academic world and while trying to lead and manage cooperative agreements. First of all, we have elaborated and tested a comprehensive theoretical model that identifies the determining factors of success of cooperative agreements between firms and research organizations.

\section{Conclusions}


Through extensive review of literature a research hypotheses were developed and the model of industry engagement was built: income and rewards, networking, access to resources, application of research, and the quest to solve industry problems are he motives behind industry engagement that consequently leads to organizational learning capability and innovation performance. This research adopted a quantitative method by using a cross-sectional design on Industry Engagement and Effective Innovation Performance. It was assumed that this study responded to these advantages. Industry engagement plays an important role in affecting organizational outcomes, such as innovation, R\&D success, increasing the efficiency of economic performance, increased number of licenses and patents, etc. In our model though we are assessing which type of engagement is more beneficial for organizational innovation. The study validates the finding of prior studies conducted through interviews with researchers' participating in the industry. Correspondingly, significant implications for organizations exist, as they are aware of which parts of their operations and conditions will drive relevant talent to engage in the organizations' work.

\section{References}

- $\quad$ Amabile, T. M., Mueller, J. S., Simpson, W. B., Hadley, C. N., Kramer, S. J., and Fleming, L. (2002). Time pressure and creativity in organizations: A longitudinal field study.

- Amara, N., and Landry, R. (2005). Sources of information as determinants of novelty of innovation in manufacturing firms: evidence from the 1999 statistics Canada innovation survey. Technovation, 25(3), 245-259.

- Argote, L., McEvily, B., and Reagans, R. (2003). Managing knowledge in organizations: An integrative framework and review of emerging themes. Management science, 49(4), 571-582.

- Balachandra, R., and Friar, J. H. (1997). Factors for success in RandD projects and new product innovation: a contextual framework. Engineering Management, IEEE Transactions on, 44(3), 276-287.

- Becker, W., and Dietz, J. (2004). RandD cooperation and innovation activities of firms - evidence for the German manufacturing industry. Research policy, 33(2), 209-223.

- Belkhodja, O., Amara, N., Landry, R., and Ouimet, M. (2007). The extent and organizational determinants of research utilization in Canadian health services organizations. Science Communication, 28(3), 377-417.

- Bozeman, B., and Gaughan, M. (2007). Impacts of grants and contracts on academic researchers' interactions with industry. Research policy, 36(5), 694-707.

- Brown, S. L., and Eisenhardt, K. M. (1995). Product development: Past research, present findings, and future directions. Academy of management review, 20(2), 343-378.

- Chaffey, D. (2002). "Achieving marketing objectives through use of electronic communications technology."

- Chaffey, D. (2011). E-business and e-commerce management. Pearson Education.

- Chaffey, D., and Smith, P. (2008). Emarketing Excellence: planning and optimizing your digital marketing. Routledge.

- Clark, R. E. (1994). Media will never influence learning. Educational technology research and development, 42(2), 21-29.

- D'Este, P., and Patel, P. (2007). University-industry linkages in the UK: What are the factors underlying the variety of interactions with industry? Research policy, 36(9), 1295-1313. 
- De Fuentes, C., and Dutrénit, G. (2012). Best channels of academia-industry interaction for long-term benefit. Research Policy, 41(9), 1666-1682.

- Deeprose, C. (2004). Giving formative feedback in higher education. Psychology Learning and Teaching, 4(1), 43-46.

- Evers, A. V. A. M., van Vliet-Mulder, J. V., and Groot, C. D. (2000). Documentatie van tests en testresearch in Nederland.

- Fournier, Susan. (1998). Consumers and Their Brands: Developing Relationship Theory in Consumer Research. Journal of Consumer Research 24 (4): 343-73.

- G. T. Waghmare, 2012). E-commerce; A Business Review and Future Prospects in Indian Business. Internet Marketing in India. Indian Streams Research Journal, vol. 2, no. IV, (pp. 1-4.

- Gangeshwer, D. K. (2013). E-Commerce or Internet Marketing: A Business Review from Indian Contextl , International Journal of $u$ - and e- Service, Science and Technology Vol.6, No.6, pp.187-194

- Giese, J. L. and J. A. Gote, (2000) .Defining Consumer Satisfaction,. Academy of Marketing Science Review [Online]00 (01)

- Gurau, C. (2008). Integrated online marketing communication: implementation and management, Journal of Communication Management, vol. 12 no. 2, pp. 169-184

- Hawkins, P., and Shohet, R. (2012). Supervision in the helping professions. McGraw-Hill Education (UK).

- Hoge, S, Cecil C. (1993). The Electronic Marketing Manual ABA Journal, 22, 175-185.

- Kevles, D. J. (1995). The physicists: The history of a scientific community in modern America. Harvard University Press.

- Kohli, A., Twyman, R. M., Abranches, R., Wegel, E., Stoger, E., and Christou, P. (2003). Transgene integration, organization and interaction in plants. Plant molecular biology, 52(2), 247-258.

- Krishnamurthy, S. (2006). Introducing E-MARKPLAN: A practical methodology to plan e-marketing activities. Business Horizons. 49(1), 49, 51, 60.

- $\quad$ Li, T., Nicholls, J. A. F., and Roslow, S. (1999). The relationships between market-driven learning and new product success in export markets.International Marketing Review, 16(6), 476-503.

- M. S. Khan and S. S. Mahapatra, (2009). Service quality evaluation in internet banking: an empirical study in India. Int. J. Indian Culture and Business Management, vol. 2, no. 1, (2009), pp. 30-46.

- Mangles, C. a. (2003). Relationship marketing in online business-to-business Markets: a pilot investigation of small UK manufacturing firms. European Journal of Marketing, Vol. 37 No. 5/6, pp. 753 773.

- Merton, R. K. (1957). Social stratification.

- Payne, G. T., Moore, C. B., Griffis, S. E., and Autry, C. W. (2011). Multilevel challenges and opportunities in social capital research. Journal of Management, 37(2), 491-520.

- Pisano, G. P. (1991). The governance of innovation: vertical integration and collaborative arrangements in the biotechnology industry. Research Policy,20 (3), 237-249.

- $\quad$ Perkmann, M., Tartari, V., McKelvey, M., Autio, E., Broström, A., D’Este, P., ... and Sobrero, M. (2013). Academic engagement and commercialisation: A review of the literature on university-industry relations. Research Policy, 42(2), 423-442.

- Prahalad, C.K. and Ramaswamy V. (2005). The Future of Competition: Co-Creating Unique Value with Customers. Boston, Massachusetts: Harvard Business School Press.

- Reinartz, Werner J. and V. Kumar. (2003). The Impact of Customer Relationship Characteristics on Profitable Lifetime Duration. Journal of Marketing 67 (1): 77-79.

- Rothaermel, F. T., and Hess, A. M. (2007). Building dynamic capabilities: Innovation driven by individual-, firm-, and network-level effects. Organization Science, 18(6), 898-921.

- Singh, J., and Agrawal, A. (2011). Recruiting for ideas: How firms exploit the prior inventions of new hires. Management Science, 57(1), 129-150.

- Subramanian, A. M., Lim, K., and Soh, P. H. (2013). When birds of a feather don't flock together: different scientists and the roles they play in biotech RandD alliances. Research Policy, 42(3), 595-612. 
- W. Tsai, S. Ghoshal, Social capital and value creation: an empirical study of intrafirm networks, Academy of Management Journal 41 (4) (1998) 464-476.

- Tzabbar, D., Aharonson, B. S., and Amburgey, T. L. (2013). When does tapping external sources of knowledge result in knowledge integration?. Research Policy, 42(2), 481-494.

- Tyagi, P. K. (1985). Relative importance of key job dimensions and leadership behaviors in motivating salesperson work performance. The Journal of Marketing, 76-86.

- Wen, J., and Kobayashi, S. (2001). Exploring collaborative RandD network:: some new evidence in Japan. Research Policy, 30(8), 1309-1319. 